\title{
Essay Writing and Its Problems: A Study of ESL Students at Secondary Level
}

\author{
Muhammad Akram ${ }^{1}$, Aisha Siddiqa ${ }^{2}$, Amana Ghulam Nabi ${ }^{1}$, Waheed Shahzad ${ }^{1} \&$ Majid Rashid $^{1}$ \\ ${ }^{1}$ Department of Humanities \& Social Sciences, Khwaja Fareed University of Engineering and Information \\ Technology, Rahim Yar Khan, Pakistan \\ ${ }^{2}$ M. Phil Scholar at National College of Business Administration \& Economics, Rahim Yar Khan, Pakistan \\ Correspondence: Muhammad Akram, Khwaja Fareed University of Engineering and Information Technology, \\ Rahim Yar Khan, Pakistan. E-mail: muhammadakramw@gmail.com
}

Received: December 29, 2019 Accepted: August 29, $2020 \quad$ Online Published: September 23, 2020

doi:10.5539/ijel.v10n6p237 URL: https://doi.org/10.5539/ijel.v10n6p237

\begin{abstract}
Writing is the most important genre of all four modules of language. In Pakistan, English is taught as a second language and developing English writing competence is essential for successful communication at all levels of the education system. However, students face challenges in mastering English essay writing skills. The main objective of this study is to investigate the challenges faced in English essay writing by Secondary school students in District Rahim Yar Khan. However, the specific objectives were to determine strategies employed by teachers for teaching essay writing skills, problems faced and strategies employed by students for learning these skills. Finally, methods were proposed for teachers and students for enhancing English essay writing skills among students. A descriptive survey research methodology was adopted. The target population was teachers and students of public secondary schools of District Rahim Yar Khan except for schools of Tehsil Liaquatpur. The sample consisted of 170 students and 27 teachers from 17 sampled schools. Questionnaire from teachers and students and an essay writing test from students were conducted to collect data. The descriptive statistical technique was used to analyze quantitative data in the form of percentages and frequencies. It was evaluated that most common teaching methods used are demonstrations, lectures and question and answers. However, effective teaching methods like oral presentations, peer teaching, group discussions, and role play are not widely used. Moreover, teachers do face problems like low salaries and high workload which effects teaching. Based on the study, recommendations were made for students, teachers, and government to address the challenges students face in English essay writing at secondary level.
\end{abstract}

Keywords: second language, English essay writing, brainstorming

\section{Introduction}

\subsection{Introduction}

Writing is one of the important language skills which is required for communication, expressing ideas and thoughts. One may write for a known audience or an unknown audience. Producing an error-free and comprehensive writing is a challenging task. To ensure academic success, it is necessary for students to enhance their writing skills which will in turn enhance their personal development too (Mukulu, 2006). Moreover, Adams (2000) concluded that enhancing writing skills can help students to deal with their academic demands and will help them in performing effectively in professional environment. In Pakistan, English is taught as a second language. It is also the official language. Students' achievement in English and other subjects are accessed through writing. Problem with second language learning is that students have difficulty in speaking and writing even after having higher education.

The problem lies because of the fact that educationist ignores English from the basic level where a child has a lot of potentials to learn many languages. In this era of competition when English is a medium of communication and academic advancement one cannot neglect the use of the English language at the basic level (Hansel, 2008). Writing is the most difficult of all the genre of language, speaking, listening and reading. Writing inspires language learners to be logical and creative in thinking. Learners are supposed to be acquiring skills by which they can express ideas clearly and effectively. In the societies where English is their native language, even their 
students cannot write English properly when they pass out from school and enter into college. There is a lack of coherence and cohesion and they even do not follow the grammatical rules (Badger, 2000).

\subsection{Research Questions}

1) What are the main factors for poor writing of Secondary students in essays in English?

2) What are the methods teachers use for teaching essay writing skills to determine their effectiveness?

3) What are the probable solutions to the challenges students face in essay writing?

\subsection{Objectives of the study}

The objectives of the study were to:

1) To determine main factors for poor essay writing of Secondary school students in English.

2) To identify the methods teachers use for teaching essay writing skills.

3) To devise a probable solution to the challenges students face in English essay writing.

\section{Method}

The nature of this survey was descriptive. The researcher has selected the mixed method approach for conducting this research keeping in view different consideration. It includes the mixing of quantitative and qualitative methods.

\subsection{Sampling of Respondents}

The target population consisted of 265 teachers of English language in the public secondary schools in Rahim Yar Khan District. The district has in total 167 secondary schools (Boys and Girls), in which 98 are Boys' and 69 are girls' schools.

Purposive and simple random sampling was used to sample teachers out as respondents in the study. In purposive sampling, sampling units are selected deliberately conforming to the criteria (Frankfort, 2005). A total of 27 teachers were selected from population of 265 teachers. Sample includes 20 male teachers and 7 female teachers. It is assumed that, on average, 2 English teaching teachers are present in Boy's schools and 1 teacher in Girl's school.

For sampling of schools to be included in study, stratified sampling technique was used. Stratified sampling has advantage that each sub group of population is represented in sample in proportion to their number in population (Kombo, 2006). Schools sample were stratified into two categories, Boys' schools and Girls' school. Stratification was important to cater each type of school into sample space. Sample space comprised of 10 boy's schools and 7 girls schools.

To sample students for this study, purposive and random sampling technique was used. In purposive sampling, sampling units are selected deliberately conforming to the criteria (Richards 2006). A sample size of 170 students was formed. On average, 10 students were sampled from each of the 17 schools. In this research, essay writing test was carried out from 150 students and the questionnaire was taken from 170 students. Moreover, a questionnaire was taken from 27 teachers. The number of sampled schools, teachers and students is shown in Table 1.

Table 1. Sampled data of teachers, students and schools

\begin{tabular}{ll}
\hline Schools & 17 \\
Teachers & 27 \\
Students & 170 \\
\hline
\end{tabular}

\subsection{Data Analysis}

The data collected from questionnaire and essay writing were analyzed to interpret the results. In this research, both qualitative and quantitative data were collected in the form of open and closed-ended questions and essay writing test. The researcher has conducted explanatory research because the objective of this study was not only to describe the problem but also to give an explanation of the phenomenon. The data were processed and tabulated using descriptive statistical techniques such as frequency and percentage. 


\section{Results}

\subsection{Findings of Written Essays}

150 Students were asked to write an essay on a topic 'My favorite book.' Purpose of this activity was to evaluate students' capability of writing and investigate common mistakes made by them in essay writing.

It is an undeniable fact that mastery overwriting cannot be achieved without effective use of grammar. Grammar is basically the set of rules which governs the principles over which sentences of a language are formed (Muriungi, 2013). Correct use of grammar requires a tough decision to be made among different forms to be used. During the evaluation of the essay, it was investigated that various mistakes made students' writing weak. Problems identified are the incorrect use of vocabulary, spelling mistakes, misuse of tenses, subject-verb agreement, and incorrect punctuation. They do have problems with organization of information and conclusion. Table 2 shows the type of mistakes made by students.

Table 2. Types of writing problems in essays

\begin{tabular}{lll}
\hline Type of writing problem & Frequency & Percentage \\
\hline Incorrect Spellings & 94 & 28 \\
Misuse of tenses & 75 & 22 \\
Punctuation and Fragment problems & 32 & 10 \\
Incorrect Prepositions & 42 & 12 \\
Pronoun & 19 & 6 \\
Misuse of Words & 48 & 14 \\
Misuse of Articles & 16 & 5 \\
Capitalization Problems & 11 & 3 \\
Total & 337 & 100 \\
\hline
\end{tabular}

From Table 2, it is obvious that spelling mistakes are the most common writing problem observed while evaluating the essays which constitutes $28 \%$ of the total mistakes made in writing. Students try to spell a word according to its pronunciation which is sometimes erroneous approach. Because of influence of other languages in English, the English spelling system has become inconsistent and has become complex for students (Muriungi, 2013).

The second major problem faced by students is the misuse of tenses. Students usually get confused in using present and past tenses in the same paragraph. Mostly, students do not know the correct usage of verb tenses and it is difficult to evaluate if the action is taking place in the past or future. Students are usually inconsistent in verb tenses. The main reasons for these grammatical problems are interference with the mother tongue of L2 learners and attitude of overgeneralization from students (Oso, 2005).

From the essays written by students, it was observed that students lack knowledge regarding use of punctuation in their writing. Almost 32 mistakes were found to be related to punctuations and fragments which correspond to $10 \%$ of overall mistakes. Incorrect use of punctuation results in multiple sentence fragments and run-on sentences. Major categories of punctuation errors are as follows:

- Proper nouns were not capitalized.

- Incorrect usage or omission of semicolon (;) and colon (:).

- New sentences were not initialized with capital letters.

- No appropriate use of the exclamation mark (!) in the essay.

- No usage of commas (,) and full stops (.), resulting in run-on sentences.

- After each introductory/opening element, commas were not used.

- Question marks (?) were hardly used.

From Table 2, it is obvious that 42 punctuation errors were found which constitute almost $12 \%$ of total errors. However, these proposition errors are further divided into three categories, addition of the preposition, and omission of preposition and misuse of a preposition.

From Table 2, it is obvious that 16 errors were made because of incorrect use of an article which constituted 5\% of total errors. Articles are divided into two categories i.e., definite article and indefinite article, and majority of students have no knowledge of them. ' $\mathrm{A} / \mathrm{an}$ ' is an indefinite article and 'the' is referred to as a definite article. It 
was concluded that most of the errors are due to the interference of the First language with the target language (English). The difference in the use of articles in Urdu and English must be taught by teachers to improve the quality of writing of their students.

Following steps should be taken by teachers and students to overcome English essay writing mistakes:

- Teachers should provide students with well-defined rules of essay writing.

- Students must practice making outline before writing the essay.

- Teachers should encourage students to practice prewriting technique.

- Students should receive clear instructions and sufficient guidance about how to perform the writing task.

\subsection{Data Analysis of Questionnaires from Students}

A questionnaire was administered in students to survey their knowledge of essay writing, the challenges they face and teachers' response to alleviate those challenges. For this purpose, five point Likert scales were used to determine the opinion of respondents.

\subsubsection{Writing Techniques Used by Students}

Students were asked that which of the essay writing technique they use while producing essays and why? Table 3 shows that $50 \%$ of students frequently use brainstorming for producing their essays. $50 \%$ of students said that they never use free writing techniques for essay writing. Only $10 \%$ of students use free writing technique for producing English essays. Only 10\% of students make mapping their choice of writing and $60 \%$ never use this in their essays. $40 \%$ sometimes make a list for writing. The choice of type of technique used by respondents shows their level or skills of writing essays and previous knowledge of specific writing technique.

Table 3. Writing techniques used by students

\begin{tabular}{lllll}
\hline Essay writing Technique & $\begin{array}{l}\text { Frequently } \\
\%\end{array}$ & $\begin{array}{l}\text { Sometimes } \\
\%\end{array}$ & $\begin{array}{l}\text { Rarely } \\
\%\end{array}$ & $\begin{array}{l}\text { Never } \\
\%\end{array}$ \\
\hline Brain storming & 50 & 20 & 20 & 10 \\
Free writing & 10 & 10 & 30 & 50 \\
Making a List & 20 & 40 & 30 & 10 \\
Mapping & 10 & 10 & 20 & 60 \\
Editing & 30 & 40 & 20 & 10 \\
\hline
\end{tabular}

\subsubsection{Challenges Faced by Student in Essay Writing}

Students were asked about the challenges they face in Essay writing at psychological level. Majority of them attributed these problems to socio-cultural issues like lack of motivation, unrealistic academic expectations, lack of confidence, writing anxiety, learning environment of classrooms and inadequate attention by teachers to individual writing skills. The findings are presented in Table 4.

Table 4. Challenges faced by student in essay writing

\begin{tabular}{lll}
\hline Challenge & Frequency & Percentage \\
\hline Lack of motivation & 87 & 51 \\
Lack of confidence & 110 & 65 \\
Inadequate learning resources & 90 & 53 \\
Lack of feedback from teachers & 140 & 82 \\
Lack of practice in English writing & 75 & 44 \\
Limited attention to individuals & 117 & 69 \\
First language interference in developing skills & 75 & 44 \\
Limited vocabulary & 142 & 83 \\
Lack of knowledge of the topics & 114 & 67 \\
\hline
\end{tabular}

87 students stated that they feel demotivated in learning writing skills which constitute $51 \%$ of total students. Students in public schools feel demotivated due to several reasons, like lack of attention from teachers in large classes. $65 \%$ of students responded that they lack confidence. Students' lack of confidence is attributed to a 
number of socio-cultural problems. These are diffidence from family, unrealistic academic expectations, and unsporting environment of classrooms.

$53 \%$ of students stated that problems in writing are indirectly related to the inadequate learning resources. In Pakistan, education system does not encourage supportive learning and interaction among respondents. Due to lack of learning material and no access of students to books in libraries, they have developed unethical traits of selfishness, the monopoly of knowledge and jealousy with other competitors. Lack of resources increases competition among students which justifies lack of collaboration among them.

$82 \%$ of students respond that teachers do not provide them with feedback on their written essays. It is problematic as students don't become aware of the knowledge that which part of essay writing they are lacking in. 44 students responded that their learning and writing skills are hindered by the interference of Urdu. Pakistani students often argue that the cultural differences between English and Urdu writing speech are the main reason for poor essay writing. As mother language is Urdu, which is also the language used in communication, students find it difficult to adopt writing rules of English.

Table 5 shows areas of English essay writing, students find difficulties in. It is observed that $75 \%$ of the students indicated that producing errorless content is the most challenging task. $70 \%$ indicated that they find difficulty in coherence. In addition, $50 \%$ of students indicated that they have issues with vocabulary. It can be solved by extensive reading and learning of correct use of new words. From Table 5, it is obvious that $30 \%$ of students have indicated problems with the conclusion and paragraphing. These issues can be resolved by making multiple drafts before producing final work, using prewriting techniques and efficient use of transitional words in the text.

Table 5. Areas of essay writing students find most challenging

\begin{tabular}{lll}
\hline Challenge & Frequency & Percentage \\
\hline Introduction & 68 & 40 \\
Content & 128 & 75 \\
Grammar & 119 & 70 \\
Conclusion & 51 & 30 \\
Coherence & 119 & 70 \\
Spellings & 102 & 60 \\
Vocabulary & 85 & 50 \\
Paragraphing & 51 & 30 \\
Punctuation & 68 & 40 \\
\hline
\end{tabular}

\subsubsection{Students' Suggestion for Improving Methods of Teaching Essay Writing}

Students' suggestion for teacher to improve teaching essay writing methods is shown in Tables 4 and 5. Majority of the students $(65 \%)$ suggested that teachers should provide feedback to individual students on regular basis. They indicate that most of the times, teachers point out general mistakes and do not provide feedback on organization of information. Moreover, $26 \%$ of students stated that teachers should pay attention to individual problems. Because of inadequate lecture duration and a large class, teachers don't attend to individual learning differences. 90 students suggested that lecture time should be more than 50 minutes so that they can discuss queries with their teachers.

Table 6. Students' suggestion for improving methods of teaching essay writing

\begin{tabular}{lll}
\hline & Frequency & Percentage \\
\hline Attention to individuals' problems & 45 & 26 \\
Feedback on regular basis & 110 & 65 \\
Rewarding system & 50 & 43 \\
Provide sufficient practice in essay writing & 113 & 67 \\
Arranging essay writing competitions & 47 & 28 \\
Oral presentations & 84 & 49 \\
Team teaching and group discussion & 105 & 10 \\
Arranging symposiums and trainings of students & 39 & 24 \\
Extensive reading & 65 & 38 \\
Adequate lecture duration & 90 & 53 \\
\hline
\end{tabular}


More than half, $67 \%$ of the students suggested that teachers should provide sufficient practice in essay writing. Students' essay writing skills can be strengthened if teachers provide them with sufficient learning material and practice. Moreover, $28 \%$ stated that essay writing competitions should be arranged at school and district levels to motivate students to secure positions. $43 \%$ suggested providing the reward to students with outstanding performance in English essay writing.

\subsection{Findings of Questionnaires from Teachers}

Teachers were given a questionnaire in order to find the challenges faced by students in writing English essays and strategies used by teachers to alleviate those challenges.

\subsubsection{Teachers' Opinion about Challenges Faced by Students}

The main objective of this study was to investigate the challenges faced by students in essay writing and propose strategies to overcome those challenges. Teachers' opinion about the challenges faced by students is shown in Table 7.

Table 7. Teachers response to challenges faced by students

\begin{tabular}{lll}
\hline Challenge & Frequency & Percentage \\
\hline Insufficient learning resources & 16 & 60 \\
Insufficient time for lectures & 16 & 60 \\
Problems in use of Grammar & 20 & 75 \\
Inadequate vocabulary & 20 & 75 \\
Anxiety & 8 & 30 \\
Lack of confidence & 9 & 33 \\
Spelling Mistakes & 12 & 45 \\
Mastery of content & 14 & 52 \\
Interference of First language & 9 & 33 \\
Lack of freedom of speech & 5 & 18 \\
Lack of extensive reading and previous knowledge & 16 & 60 \\
Students negative behavior toward learning & 18 & 65 \\
\hline
\end{tabular}

16 teachers stated that problems with students writing are because of inadequate resources and time. Teachers only have a lecture time of 40-50 minutes they have to interact with a large number of students within this short time and provide feedback to individuals. $75 \%$ of teachers indicated that students find it challenging to overcome grammatical errors and inadequate vocabulary. Students' do not learn the context of grammar and try to memorize it.

Lack of confidence and motivation are the reasons behind problems faced by students in writing an essay as indicated by 9 teachers. This diffidence is due to lack of attention from parents, unsupportive learning environment of classrooms, and no use of teaching methods like oral presentations and group discussions. $60 \%$ of teachers have attributed the lack of extensive reading and topic-specific knowledge to problems in creative writing. As students lack reading habits, they face problems related to topics specific knowledge, organization, coherence and cohesion, grammar, vocabulary, paragraphing and punctuation.

\subsubsection{Problems Faced by Teachers at the Teaching Level}

Teachers were asked to describe problems they face teaching students. $80 \%$ of the teachers stated problems that affect the teaching of essay writing to students such as high working load, insufficient duration of lecture, teachers' disheartenment towards the teaching of essay writing, and inadequate professional development.

\subsubsection{Teachers' Suggestions for Improving Essay Writing}

Teachers were asked about the suggestions and measures they put in place to resolve challenges students face in writing English essays. These suggestions are presented in Table 8. 
Table 8. Teachers' suggestions for improving essay writing skills

\begin{tabular}{lll}
\hline Suggestions & Frequency & Percentage \\
\hline Arranging internal symposiums & 5 & 20 \\
Group discussions & 27 & 100 \\
Encouraging extensive reading & 22 & 80 \\
Remedial teaching & 14 & 50 \\
Rewarding students with best essay & 5 & 20 \\
Discussing best and worst essays in classroom & 19 & 70 \\
Arranging essay writing competition & 14 & 50 \\
Adequate feedback system and attention to individual learning differences & 19 & 70 \\
Arranging oral presentations and role play & 11 & 40 \\
\hline
\end{tabular}

22 teachers suggested that they should encourage students for extensive reading. It will not only increase their topic-specific knowledge but also help them in understanding sentence structures, learning new vocabulary and their use in writing, paragraphing and organization of information. $40 \%$ indicated that they should arrange oral presentations, role play for encouraging students to participate in classroom activities and it will increase their confidence.

The arrangement of essay writing competitions should be done to motivate students to participate and topics should be based on creative writing rather than rote learning as suggested by 14 teachers. 19 teachers were of the opinion that they should discuss the best and worst written essays in classrooms. 5 teachers suggested a reward system to appreciate and motivate students.

$90 \%$ stated that provisions of adequate feedback and attention to individuals be made to help them in overcoming writing problems. Moreover, students should be motivated by giving encouraging remarks and rewards. Based on the above results, it is evident that teachers should employ all the learning strategies to help the student in overcoming challenges they face in every phase of creative essay writings.

\section{Conclusions}

The following conclusions were deduced from the research:

- Based on the findings, lecture, question, and answers, reading aloud and demonstrations are the most common teaching techniques used by teachers. All these conventional methods promote rote learning and hinder creative writing capabilities of students. Moreover, teachers focus on correct use of grammar rather than developing mastery over content and organization of ideas.

- Methods like role play, peer teaching, group discussions, and oral presentations are given less importance in teaching writing skills.

- Teachers do not provide feedback to students on regular basis and don't pay attention to individuals learning differences. Oral and written feedback should be given to students. These feedbacks should be constructive for students to overcome the challenges they face in essay writing.

- Teachers should discourage rote learning or memorizations and use strategies that promote creative writing.

- High workload, inadequate lecture duration, and insufficient professional development are the problems teachers face in teaching which effects writing capabilities of students.

- Teachers face socio-economic problems like low monthly income, high living costs, and inadequate learning resources like outdated books which indirectly effects the learning of students.

- Greatest challenges faced by students are first language interference, content mastery, and correct use of grammar. These methods lead to low scores and large errors in essay writing. These are partly related to the conventional methods used by teachers.

- Students do not exploit all the language learning strategies. They depend on individual learning strategy like making notes. Students should employ interactive learning methods like group discussion, team writing and peer teaching to overcome deficiencies in writing.

- Students face the challenge of limited vocabulary, the organization of ideas, misuse of words and spelling mistakes. These problems can be overcome by extensive reading.

In order to improve English essay writing skills of students, the following recommendations should be taken into consideration: 
- Teachers should use process-based approaches like group discussions, peer teaching, oral presentations in the learning of writing skills to promote creative writing.

- Rote learning is promoted as essays are repeated in exams. So, reforms must be made in education system on emergency basis to stop the repetition of essays.

- Essay writing competitions must be arranged at the district level and reward should be given to participants it will motivate students and boost their confidence.

- Lecture duration should be increased and the number of students in each class should be limited to 30 students. It will help teachers to attend to individual learning problems.

- Government must induct qualified English teachers to reduce the workload on currently employed teachers. Moreover, the salaries of teachers should be increased and pieces of training should be arranged for their professional development.

- Government should establish libraries in each school. Teachers must encourage students to read written material like newspapers, books, and magazines. This extensive reading will help students in developing writing skills.

\section{References}

Adams, K. K. (2000). Research and writing across the disciplines. California: Mayfield Publishing Company.

Badger, R. W. G. (2000). A Process genre approach to teaching writing. ELT Journal, 54, 153-160. https://doi.org/10.1093/elt/54.2.153

Frankfort, C. N. (2005). Research methods in social sciences (5th ed.). London: Arnold.

Hansel, P. R. (2008). Common students writing problems. Retrieved from http://www.paulhensel.org/teachprob.html

Javid, C. Z. a. U. M. (2014). Saudi EFL Learners'Writing Problems: A Move Towards Solution. Retrieved from Saudia Arabia:

Kombo, D. K., \& Tromp, D. L. A. (2006). (2006). Proposal and thesis writing: An introduction. Retrieved from Nairobi.

Kroll, B. (2003). Exploring the dynamic of second language writing. Cambridge University Press. https://doi.org/10.1017/CBO9781139524810

Mukulu, E. I. (2006). KCSE revision English. Retrieved from Nairobi:

Muriungi, P. K. (2013). The influence of mother tongue maintenance on acquisition of English language skills among day secondary school students in Imenti South district, Kenya. International Journal of Linguistics, 5, 21-27. https://doi.org/10.5296/ijl.v5i1.3318

Oso, Y. W., \& Onen. (2005). A General guide to writing research proposals and report. Retrieved from Nairobi.

Rao, Z. (2007). Training in brainstorming and developing writing skills. ETL Journal, 61(2), 44-51. https://doi.org/10.1093/elt/ccm002

Richards, L. C. (2006). Reflective teaching in second language classrooms. Retrieved from New York.

Saunders, M. (2009). Research methods. Retrieved from Harlow Essex.

\section{Copyrights}

Copyright for this article is retained by the author, with first publication rights granted to the journal.

This is an open-access article distributed under the terms and conditions of the Creative Commons Attribution license (http://creativecommons.org/licenses/by/4.0/). 